\title{
REPENSAR AS RELAÇÕES SOCIAIS DE SEXO, CLASSE E "RAÇA" NA GLOBALIZAÇÃO NEOLIBERAL ${ }^{1}$
}

\author{
Jules Falquet ${ }^{2}$
}

\begin{abstract}
Resumo
A autora procura demonstrar como funciona a co-formação das relações de poder (relações sociais de sexo, de "raça" e de classe), a partir da análise da re-organização da divisão do trabalho e, mais particularmente, do "trabalho considerado feminino", uma e outra provocadas pela globalização neoliberal e que, ao mesmo tempo, modificam aquelas relações.

Palavras-chave: Feminismo. Globalização. Relações de Poder.
\end{abstract}

\footnotetext{
${ }^{1}$ Tradução de Renata Gonçalves; revisão de Sávio Cavalcante. Artigo publicado em francês In: DORLIN, Elsa (org.). Sexe, classe, race. Pour une épistémologie de la domination. Paris: PUF, 2008. Este texto não poderia ter sido escrito sem as inúmeras discussões, notadamente nos grupos de estudo sobre sexo e raça de Toulouse; Sexismos e colonialismo de Paris; no seminário do CEDREF sobre a rearticulação das relações de sexo, "raça" e classe no contexto da globalização neoliberal; no RT 24 da Associação francesa de sociologia e nas revistas Nouvelles Questions Féministes e Cahiers du Genre. Sou particularmente grata a Nasima Moujoud por nossas profundas trocas sobre o assunto. Sabreen Al Rassace, Malika Bakhouche, Milena Jacsic, Françoise Guillemaut, Salima Mousli e Martine Stutz me ajudaram a pensar os laços entre migração, trabalho doméstico e trabalho do sexo. Ochy Curiel, Mercedes Cañas, Sabine Masson et Melida me reconfortaram em minha reflexão crítica sobre as feministas face às trabalhadoras domésticas migrantes e/ou racializadas. Por fim, este texto deve muito aos comentários de Anissa Hélie, Paola Bacchetta e Florence Degavre.

${ }^{2}$ Professora de sociologia na Universidade Paris-Diderot; pesquisadora do Centre d'Enseignement, de Documentation et de Recherches pour les Études Féministes (CEDREF), França.
} 


\begin{abstract}
s
The author attempts to demonstrate how the co-formation of relations of power (social relations of sex, "race" and class) functions, using an analysis of the reorganization of the division of labor and, more specifically, of "women's work," both of which are provoked by neoliberal globalization and which, at the same time, modify those relations.
\end{abstract}

Keywords: Feminism. Globalization. Power Relations.

Às imigrantes "sozinhas", à Rede para a autonomia jurídica das mulheres imigrantes, refugiadas e exiladas (RAJFIRE) e à Flora Tristan, a primeira a ter enfatizado, desde 1835, a necessidade de boa acolbida às mulheres estrangeiras

$\mathrm{P}$ ara situar minha abordagem, é necessário enfatizar que sou mulher, universitária, branca, de nacionalidade francesa e vivendo hoje na França, envolvida nesta reflexão teórica, mas também política. Desde o Primeiro Encontro Internacional contra o Neoliberalismo e pela Humanidade, convidada pelo movimento zapatista de Chiapas em 1996, me esforço em analisar a globalização neoliberal com instrumentos fornecidos tanto por um conjunto de movimentos sociais "progressistas" da América Latina e do Caribe (o movimento zapatista mexicano, o movimento dos Sem-Terra do Brasil e os movimentos feminista e lésbico do continente) como por inúmeras feministas negras ou "racializadas". No entanto, é difícil apresentar uma análise unificada, tamanha são as complexidade, a contradição e oma permanente processo. Todavia, a globalização neoliberal é para mim a ocasião de constatar as insuficiências gritantes de três grandes correntes de análise às quais me ligo: o materialismo histórico, o feminismo radical e o antiimperialismo-anticolonialismo.

São sobretudo as interpelações das feministas racializadas e/ou proletárias e/ou lésbicas que devem, a meu ver, ser ouvidas e estudadas, se desejamos produzir uma teoria e uma prática úteis à transformação social radical mais do que nunca necessária. Em particular, acho indispensável integrar plenamente em nossas análises os efeitos conjugados de várias relações sociais de poder: de sexo (incluso a sexualidade), de classe e de "raça". Parto da hipótese de que estas relações não 
são nem simplesmente superpostas ou adicionadas, nem intersecções (CRENSHAW, 1995). Considero-as mais imbricadas 3 e até consubstanciais (KERGOAT, 2008) e co-formadas (BACCHETTA, 2006). Tentarei demonstrar como funciona esta coformação a partir de um objeto concreto: a re-organização da divisão do trabalho provocada pela globalização neoliberal, e mais particularmente, do "trabalho considerado feminino", que, simultaneamente, modifica as relações de sexo, de "raça" e de classe.

A globalização com certeza não é algo radicalmente novo: sua raiz está na longa história do capitalismo, da escravidão, da colonização-descolonização e das mutações dos sistemas patriarcais. Entretanto, ela produz profundas transformações. Os discursos otimistas, de legitimação desta globalização, falam de extensão da democracia, de "participação", de igualdade e de prosperidade crescente para todas e todos. As análises críticas, empíricas, enfatizam mais o fosso vertiginoso das desigualdades e da exploração de sexo, de classe, de "raça" e Norte-Sul5. Interrogam-se igualmente sobre as recomposições em marcha: as classes sociais desapareceram? Um novo proletariado está surgindo? Quem o compõe? 0 racismo mudou: está menos biológico e mais "cultural", mas sempre vivo. Como ele opera hoje? Enfim, ouvimos sempre dizer que a igualdade dos sexos nunca esteve tão próxima, ao mesmo tempo em que sabemos que as mulheres, as adolescentes e as sexagenárias constituem a imensa maioria das pessoas mais empobrecidas do planeta. Como explicar isto?

Procederei em dois tempos. Primeiro, enfatizando as contribuições e insuficiências dos estudos sobre a globalização neoliberal que tentam interpretála como transformação do "sistema-mundo" e como internacionalização da reprodução social. Em seguida, proporei algumas pistas para repensar a "regra do jogo" hoje dominante: de um lado, a necessidade de apreender o continuum que liga trabalho doméstico, sexual e "reprodutivo", mesmo quando exercidos por todo tipo de pessoas em lares bem mais vastos e abertos que o que costumamos considerar; de outro, o papel do Estado-nação, com base num sistema político

\footnotetext{
${ }^{3}$ Para a primeira formulação do conceito, ver Combahee River Collective (1986 [1979]).

${ }^{4}$ Utilizo o termo "raça" entre aspas para sublinhar o caráter eminentemente social, artificial e compósito. Como veremos, a "raça" reagrupa notadamente as relações de poder relacionadas à "cor" e à etnicidade, mas também à nacionalidade e ao status legal.

${ }^{5}$ Como Chandra Mohanty (2003), emprego os conceitos Norte, Sul, Oeste, Oriente, Ocidente, num sentido político e não geográfico.
} 
heterossexual, na organização da circulação e da capacidade jurídica das pessoas.

\section{OS LIMITES DO EXISTENTE}

Aceitamosparcialmente a análisedeMarx, deBraudel (1985) edeWallerstein (1974, 1980, 1989), assim como as teorias da dependência e seus avatares, que lêem vastas páginas da história planetária como efeitos da expansão do sistema-mundo capitalista - mesmo se esta expansão não é linear, se outros múltiplos fatores entram no jogo e se o mundo "ocidental" onde se desenvolveu o capitalismo está longe de ser o centro da história, como bem enfatizou Gilroy (2003 [1993]) ou Chaudhuri (1990). Todavia, duas acepções centrais das teorias do sistema-mundo capitalista são problemáticas. Primeiro, a idéia de uma "proletarização" crescente e inevitável da mão-de-obra: nos fatos, ela não aconteceu. Ou, mais precisamente, que podemos compreender por "proletarização"? Em seguida, a idéia segundo a qual a passagem do feudalismo para o capitalismo teria necessariamente reduzido as relações sociais não-capitalistas ao estado de sobrevivências chamadas a uma rápida extinção e marginais na análise - ora, estas relações manifestamente subsistem.

Como veremos, é precisamente esta co-formação das relações de produção capitalista (as relações de exploração assalariada) e das relações de produção "nãocapitalistas", as relações de apropriação - servidão, escravidão e "sexagem", como magistralmente demonstrados por Colette Guillaumin (1992 [1978]) - que

\footnotetext{
${ }^{6}$ Em um de seus principais livros, Sexe, race et pratique du pouvoir. L'idée de nature, Colette Guillaumin cunha a idéia de que as mulheres constituem uma classe social de sexo apropriada pela classe dos homens através da relação social de sexagem, tanto individual (matrimônio heterossexual) como coletiva (por exemplo, o caso das mulheres solteiras ou das freiras). Sexagem é a apropriação do corpo, dos produtos do corpo, do tempo e da energia psíquica da classe das mulheres por parte da classe dos homens (GUILLAUMIN, 1992 [2005], primeira edição é de 1978). Guillaumin constrói o conceito de sexagem (sexage em francês) para se referir a relações de apropriação física direta de pessoas de um grupo social por pessoas de outro grupo social; logo, sexagem é uma relação social "oposta" à exploração salarial, em que ocorre um pagamento em dinheiro e cuja apropriação é só a da força de trabalho e não a do corpo e da pessoa inteira. 0 conceito de sexagem recorda outros dois casos históricos de relações de apropriação física direta: a servidão, que era a condição de quase escravidão de servas e servos da época feudal da Europa do Oeste durante a Idade Média, e a escravidão (esta se refere ao sistema escravista de plantações que se desenvolveu no auge da colonização do continente americano e do tráfico negreiro, cujo apogeu coincicide com o século XVIII).
} 
deve estar no coração de nossa análise. De fato, toda a questão é de saber como são co-construídas a extração de trabalho mediante salário, a extração do trabalho gratuito e, principalmente, tudo o que se encontra entre estes dois "extremos" e que denominaremos "trabalho desvalorizado". Nossa hipótese é que a globalização neoliberal empurra hoje a maior parte da mão-de-obra "no centro" rumo a um trabalho que não é totalmente gratuito, mas que também não é "corretamente" remunerado e que nem é, nem nunca será, plenamente "proletário".

\section{A. INCORPORAR "RAÇA” ÀS ANÁLISES MARXIANAS?}

Para compreender a "crise" do capitalismo, Balibar e Wallerstein, em uma obra que se tornou clássica, Race, nation, classe: les identités ambiguës (1988), propõem uma série de hipóteses sobre o surgimento de um "novo racismo" (BALIBAR) e sobre o papel do "lar doméstico" (WALLERSTEIN). Eles constatam que a "proletarização" anunciada por Marx não aconteceu como previsto. Observam que uma das principais contradições do capitalismo é a necessidade de arbitrar entre interesses a curto e a longo prazos (maximizar a mais-valia diminuindo os salários e por meio do trabalho gratuito, ao mesmo tempo em que mantém uma demanda solvável para consumir as mercadorias produzidas). 0 sistema capitalista deve então organizar a permanente "transformação social de certos processos de produção de trabalho não-assalariado em trabalho assalariado (...). É isto que queremos expressar ao falar de 'proletarização"' (WALLERSTEIN, 1997 [1988], p. 164-165). Mas paradoxalmente, "o aspecto principal da proletarização (...) não é, [segundo Wallerstein] a generalização do trabalho assalariado" (BALIBAR, 1997 [1988], p. 20) ${ }^{7}$. Assim, Balibar e Wallerstein fazem aparecer entre o trabalho nãoassalariado e o trabalho assalariado uma providencial figura que permite regular esses "vasos comunicantes" e que proponho denominar "trabalho desvalorizado". Se Balibar e Wallerstein não o definem na seqüência, de minha parte considero crucial colocá-lo a cerne do debate, tanto quanto as pessoas chamadas a realizá10.

Qual é, de fato, a mão-de-obra empurrada a este tipo de trabalho? Segundo Wallerstein, "o racismo é a fórmula mágica (...) que permite alongar ou contratar (...) inúmeros disponíveis para salários os mais baixos e as funções

\footnotetext{
${ }^{7}$ Eles até afirmam que, se "nós devemos definir o proletariado como [a classe] que cede a outros uma parte do valor produzido por ela [...], a ausência de pagamento de um salário ao produtor não impede que este seja definido como proletário" (WALLERSTEIN, 1997 [1988-1979], p. 162).
} 
econômicas menos gratificantes. (...) Para um segmento importante da força de trabalho, este justifica que seja atribuída uma remuneração de longe inferior à do critério meritocrático" (WALLERSTEIN, 1997 [1988], p. 49-50). Balibar completa a análise afirmando que o racismo "clássico" se transformou a partir dos anos de 1980 em racismo contra a população migrante, que opera uma fusão (em potencial, sempre presente) entre "raça" e classe: "o racismo antiimigrantes realiza a identificação máxima da situação de classe e da origem étnica (cujas bases reais sempre existiram na mobilidade inter-regional, internacional ou intercontinental da classe operária, ora massiva ora residual, mas jamais abolida, o que é precisamente um dos traços especificamente proletários de sua condição" (BALIBAR, 1997 [1988], p 275).

Desta maneira, Balibar e Wallerstein colocam claramente as relações sociais de raça como continuidade das relações de classe. No que tange às relações sociais de sexo, sua análise é bem menos convincente. No capítulo "Universalismo, racismo, sexismo: as tensões ideológicas do capitalismo", Wallerstein afirma que: "o que chamei de etnicização da força de trabalho tem por objetivo tornar baixíssimos os salários de todos os segmentos da força de trabalho. Tais baixos salários só são possíveis porque os assalariados são mantidos em estruturas familiares [... que] necessitam de um investimento considerável de trabalho nas atividades ditas de 'subsistência', não apenas do homem, mas, em grande medida, da mulher, das crianças e até de idosos..." (WALLERSTEIN, 1997 [1988], p 50)․ Nem ele nem Balibar fazem no resto da obra a menor alusão às inumeráveis teorias feministas que, no entanto, enfatizaram quase a exaustão que as relações sociais de sexo também permitiam "como num passe de mágica" que seja atribuida às mulheres uma remuneração de longe inferior àquela que o critério meritocrático jamais faria jus.

Outros analistas desenvolveram estas proposições de Balibar e Wallerstein, mostrando como essas leis e as políticas migratórias criam diferentes categorias de imigrantes", incluindo o(a)s "sem documentos" (FASSIN et alli, 1997), o que permite dividir e enfraquecer ainda mais a classe". Alguns/algumas colocam em evidência fenômenos novos como a "deslocalização num mesmo local" (TERRAY, 1999). Outros, ainda, ao sublinhar as continuidades entre escravidão e

${ }^{8} 0$ autor complementa, sem maiores aprofundamentos: "0 sexismo está acompanhado do "etarismo"” (idem, p. 51).

${ }^{9}$ A palavra em francês permite à autora fazer a distinção entre os sexos: immigrée-e-s [N.T.] 
assalariamento, fazem aparecer o "assalariado de cabresto", apoiado no racismo das políticas migratórias, como um potente mecanismo de regulação do salariado clássico (MOULIER BOUTANG, 1998).

Vemos que estas análises tentam compreender como as classes e o salariado são modificados pela nova gestão da mobilidade da mão-de-obra, ou seja, por políticas migratórias cada vez mais restritivas organizadas em torno de uma redefinição do racismo e produtoras de diversas categorias precarizadas. Todavia, não conseguem abarcar plenamente um fenômeno concomitante: o fato de que uma considerável proporção da migração é feminina. Ravenstein havia mostrado, no entanto, desde 1885, que em curtas distâncias as mulheres migravam até mesmo mais que os homens. Hoje, torna-se quase impossível escamotiar esta questão: a própria ONU afirma que a metade das migrações internacionais é feita por mulheres (que continuam também a se deslocar no interior de cada país).

\section{B. INTERNACIONALIZAÇÃO DA REPRODUÇÃO SOCIAL: O SEXO DAS}

\section{POLÍTICAS SOCIAIS, MIGRATÓRIAS E DO TRABALHO}

Para analisar não mais a crise do capitalismo e sim a globalização triunfante, Saskia Sassen (1991), no mesmo período de Balibare Wallerstein, propôs uma reflexão pioneira sobre os "bastidores" da hiper-mobilidade dos capitais e dos quadros altamente qualificado(a)s. Evidenciou a existência de uma mão-de-obra migrante e precarizada, mojoritariamente feminina e do Sul (racializada), para assegurar a baixo preço o trabalho subterrâneo, invisível, freqüentemente informal e, no entanto, indispensável à globalização nas metrópoles globais. Tornando visíveis estes circuitos alternativos da globalização, a autora abriu caminho a outras análises da internacionalização do trabalho de reprodução social.

Inúmeras pesquisadoras debruçaram-se sobre a redistribuição das mulheres do Sul, as migrantes do "trabalho sujo", particularmente do trabalho doméstico (ANDERSON, 2000; CHANG, 2000; HONDAGNEU-SOTELO, 2001; PARREÑAS, 2002). Outras analisaram a transferência do trabalho de cuidar de crianças para as "nannies" e babás imigrantes, cujo amor maternal é construído como uma característica natural, como mulher e como originárias de "culturas" que valorizam a maternidade e 0 amor (HOCHSCHILD, 2002). A exploração de seu trabalho e de seu amor provoca em cascata novas transferências de mão-de-obra, que Hochschild caracteriza como "cadeias de care globais" (2000). 
Estas análises devem ser inseridas numa reflexão geral sobre a reorganização do trabalho conduzido pela plataforma neoliberal do Estado, que consiste em não mais asseguar uma grande parte dos serviços, principalmente do trabalho de reprodução social. Enquanto Sylvia Walby mostrara desde 1990 que a Grã-Bretanha havia passado, com o desenvolvimento do Welfare State, de um patriarcado privado a um patriarcado público, a queda dos sistemas "socialista" no mundo e o desmantelamento do pacto social-democrata na Europa deslocaram esta enorme sobrecarga de trabalho para o setor privado e para a família. Ora, a novidade não é que a classe dos homens tenha se desvencilhado deste trabalho transferindo-o à classe das mulheres, mas sim a maneira como as mulheres dos países industrializados e as mulheres privilegiadas dos países do Sul tenham sido levadas a também empurrar este trabalho para outras pessoas, principalmente mulheres imigrantes (ilegais ou não), como oferta em bandeja de prata pelas políticas migratórias e sociais dos diferentes Estados, tanto importadores como exportadores de mão-de-obra (WALBY, 1997; MARCHAND \& SISSON RUNYAN, 2000). De fato, não se trata somente de constatar que as mulheres são margem de manobra sonhada pelo sistema, amortecendo a crise por meio de seu sobretrabalho mal-pago (ATTAC, 2003; BISILLIAT, 2003; FALQUET et alli, 2006; HIRATA \& LE DOARÉ, 1998; TGS, 2001; WICHTERICH, 1999), mas de saber como o sexo, a "raça" e a classe são mobilizadas e reorganizadas para construir uma nova divisão social do trabalho ao nível da familia, de cada Estado e do conjunto do globo.

Diane Sainsbury (1993) foi uma das primeiras a interrogar as diferentes formas de Welfare State em função do que estas trazem não tanto em termos de desmercantilização, mas de desfamiliarização das tarefas de reprodução social. Outras, na sequiência, analisaram os laços entre a organização da reprodução social em cada estado, o tipo de care requirido e o tipo de migração feminina "peneirada" para responder às necessidades de care de diferentes Estados. Assim, Eleonore Kofman et alli (2001) descreveram a gestão sexuada das migrações internacionais na Europa em função das evoluções das políticas de Welfare, enquanto Francesca Bettio \& Janneke Plantenga (2004) trabalhavam sobre os diferentes regimes de care, depois sobre o care drain ${ }^{10} \mathrm{e}$ as migrações femininas no sul da Europa (BETTIO \& SIMONAZZI, 2006), ou outras ainda se debruçaram no estudo dos cuidados aos idosos (por exemplo, DEGAVRE \& NYSSENS, 2007).

${ }^{10}$ Em inglês no original [N.T.]. 
Outra importante pista foi fornecida por Evelyn Nakano Glenn para os Estados Unidos, seguida às primeiras observações feitas por Angela Davis (1983). Glenn estabelece os laços entre a "raça", o gênero e a inserção no mercado de trabalho. Ela destaca a pertinência histórica, desde a escravidão, da destinação de certas categorias de população - as mulheres, o(a)s negro(a)s - a um trabalho de care extorquido. Sobretudo, ela mostra como o Estado e a lei privam de direitos e de cidadania as categorias da população destinadas ao care - da escravidão à servidão sob cintrato, até hoje. Esta reflexão permite desenvolver a análise em duas direções. Primeiro, as relações entre colonização, escravidão, políticas migratórias e privação de direitos e de cidadania para vastos setores da população mundial. Em seguida, os laços entre o discurso da cidadania, da democracia e da ética do care, como os textos reunidos por Laugier e Paperman (2005) permitem pensar. Aqui se trata de ver como esses discursos se juntam na emergência de um novo modelo pós-social-democrata que se busca legitimar.

\section{Desvendar as Regras do jogo?}

\section{A. Para UMA CONCEITUALIZAÇÃO DO "TRABALHO CONSIDERADO FEMININO"}

As análises da internacionalização da reprodução social tendem a manter uma separação analítica entre as três grandes tarefas geralmente devolvidas às mulheres: 0 trabalho de manutenção dos membros do grupo familiar, o trabalho sexual e o trabalho de criação das crianças. Certamente, as feministas materialistas destacaram desde muito cedo os laços entre estes três domínios. Colette Guillaumin (1992 [1978]) mostrou como a sexagem permitia a apropriação conjunta do corpo e de seus produtos, da sexualidade e da força de trabalho. Por sua vez, Paola Tabet estudou, de um lado, a reprodução das mulheres como um trabalho no sentido marxiano (2002 [1985]), e, de outro, a troca econômico-sexual entre mulheres e homens como um continuum ligando as "putas" e as mulheres casadas todas fornecendo, em proporções variadas, uma combinação de trabalho sexual e de trabalho "doméstico" e emocional (2004). No entanto, suas duas análises permaneceram justapostas. Gail Pheterson (2001 [1996]), de sua parte, mostrou como o estigma da prostituta, suscetível de se aplicar a todas as mulheres, permite restringir a mobilidade das mulheres.

Hoje importantes trabalhos evidenciam continuidades entre o emprego doméstico e diversas formas de prostituição, estas duas atividades sendo exercidas 
sucessiva ou simultaneamente por certas imigrantes (OSO, 2003), em especial as mulheres vindas "sozinhas" (MOUJOUD, 2007), sobretudo quando as legislações migratórias e do trabalho as preacrizam e as empurram para a ilegalidade e a clandestinidade $^{11}$ - estando a maior parte das imigrantes reduzidas pela lei a um estatuto de dependente de pais ou de maridos ${ }^{12}$. No que tange ao trabalho de produção de crianças, uma vez colocados os laços estreitos que unem nacionalismo e intervenções sobre a reprodução das mulheres (YUVAL-DAVIS, 1991), análises feministas mostraram conexões entre novas tecnologias reprodutivas e nacionalismo, sob o controle do Estado (KAHN, 2007 - com relação a Israel). Outros estudos insistem sobre o papel das instituições internacionais na promoção de políticas demográficas sexistas e racistas à escala planetária (FALQUET, 2003; STRÖBL, 1994). Parece-nos necessário fazer a síntese dessas análises empurrandoas a três direções.

Primeiro, reconhecendo a existência de um verdadeiro continuuum entre essas três formas de trabalho: o trabalho de manutenção (doméstica e/ou comunitária), o trabalho sexual e o trabalho de produção/cuidado dos filhos. 0 fenômeno dos mail-orders brides ${ }^{13}$ - em que mulheres de países empobrecidos tentam, por meio do casamento, trocar suas disponibilidades para o desempenho destes três tipos de trabalho), não somente contra a famosa "manutenção" analisada por Delphy (1998), mas contra a nacionalidade de múltiplas vantagens de um(a) autóctone de um país superdesenvolvido - poderia ser uma porta de entrada para esta análise, a partir das novas formas de mobilidade internacional das mulheres no contexto neoliberal ${ }^{14}$. Proponho denominar este continuum de trabalho, remunerado ou não, de "trabalho considerado feminino". Este constitui a maior parte do "trabalho desvalorizado" que Balibar e Wallerstein colocavam como principais executores a população imigrante. A perspectiva da co-formação das relações de poder explica que este trabalho pode ser exercido por indivíduos do sexo masculino, sobretudo se forem etnicizados e naturalizados com este objetivo

${ }^{11}$ Com relação às “trabalhadoras do sexo”, ver Guillemaut (2007).

12 Sobre a legislação na França, consultar Lesselier (2003).

${ }^{13}$ Em inglês no original [N.T].

14 É claro que a "circulação" violenta das mulheres durante os processos de colonização, de escravidão, de guerras de conquistas e "limpezas étnicas" que precederam a atual globalização (e outros processos contemporâneos) mereceriam ser analisados com as mesmas ferramentas, mas isto ultrapassa amplamente as possibilidades do presente artigo. 
(imigrantes, escravos ou colonizados), mas explica principalmente que a imensa maioria deste trabalho permanece sob a responsabilidade por excelência das pessoas socialmente construídas e consideradas mulheres.

Em seguida, é importante vermos que papel desempenham tanto os Estados como as instituições internacionais na gestão global da mão-de-obra, por meio das políticas demográficas, migratórias e de mão-de-obra (organização dos serviços públicos e do mercado de trabalho) - mas também por meio do reforço do militarismo (ENLOE, 1989, 2000), do aumento das guerras, dos deslocamentos populacionais e dos campos de refugiado(a)s político(a)s (AGIER, 2003), ou ainda do fechamento massivo de certos setores da população (para os Estados Unidos, campeões no assunto, ver DAVIS, 2006). De mãos dadas, Estado e instituições internacionais participam igualmente, no contexto de novas políticas de "desenvolvimento", na promoção do turismo e do desenvolvimento concomitante do trabalho do sexo (FALQUET, 2006). Enfim, também por meio da Organização Internacional do Trabalho (OIT), Estados Unidos e instituições internacionais planejam a inserção das mulheres no trabalho. Assim, os países da OCDE fixaram a si mesmos o objetivo de terem $60 \%$ das mulheres no mercado de trabalho em 2010 (objetivo de Lisboa, 2000). Estados e instituições internacionais tentam apresentar esse projeto como o desdobramento das reivindicações por igualdade das mulheres e o coroamento de um modelo social-democrata sensível ao gênero - retornaremos a este tema, central em sua tentativa de legitimação da nova ordem mundial pós-Welfare State.

Por fim, é preciso re-conconceituar o lar "doméstico". De fato, não somente suas dinâmicas são profundamente marcadas pelas políticas públicas nacionais e internacionais, como sua composição e seus limites não são as que geralmente servem de paradigma para a análise. Primeiro, a maioria dos lares se distanciam consideravelmente dos modelos "ocidentais" de família nuclear que serviram de base a várias construções teóricas, como foram mostrados nos trabalhos das Black feminists (HILL COLLINS, 2005) e de inúmeras feministas do Sul. Em seguida, um bom terço dos lares no mundo não são mais dirigidos por homens e sim por mulheres (BISILLIAT, 1996). Sobretudo porque a globalização modifica profundamente seu equilíbrio, introduzindo fisica ou pontualmente cada vez mais estrangeiro(a)s que contribuem fortemente para a realização do trabalho que se espera ser realizado. Dentre este(a)s estrangeiro(a)s, encontramos as empregadas domésticas imigrantes (vindas da zona rural ou do exterior), as cuidadoras de doentes e as enfermeiras, mas também jardineiros, office-boys ou motoristas, 
ou ainda mães de aluguel e trabalhadoras do sexo, que fornecem imagens pornográficas ou serviços sexuais em domicílio ou na ocasião de deslocamentos para lazer. Aqui, as relações Norte-Sul são flagrantes, mas é preciso observar que esta divisão do trabalho se organiza igualmente à escala de cada país, em função de sistemas racistas, de classe, de casta e colonizados.

Por outro lado, é preciso pensar estas questões não somente para os lares privilegiados do Norte e do Sul, mas também para outros. Um estimulante trabalho de síntese feito por Laura Oso (no prelo) mostra que os diferentes "lares transnacionais" (poderíamos completar "trans-regionais") criados pela migração neoliberal são centrais para compreender as estratégias de reprodução dos lares e dos Estados tanto do Norte como do Sul. Oso mostra, sobretudo, que esses lares são uma das chaves empíricas e teóricas da análise de uma dupla imbricação. De um lado, entre reprodução do Sul e reprodução ao Norte. De outro lado, entre reprodução gerida no seio de uma família e reprodução gerida pelo Estado.

\section{B. HETEROSSEXUALIDADE E CO-FORMAÇÃO DAS RELAÇÕES DE PODER}

Um espectro ronda as teorias da co-formação das relações de poder: 0 da heterossexualidade. Esse conceito de heterossexualidade foi forjado pelas lésbicasfeministas, das quais Monique Wittig permanece a principal teórica (2001[1980]). Ao contrário do uso corrente que enfraquece consideravelmente seu alcance, a heterossexualidade de que falamos tem pouco a ver com as pulsões e práticas sexuais: trata-se de uma potente instituição social, amplamente endossada ao Estado e à Nação e que desempenha um importante papel na circulação de pessoas. Veremos que ela contribui de modo central não somente na organização da aliança, da filiação e da herança, mas de modo mais fortemente ainda na construção e na naturalização dos sexos, mas também das raças e das classes.

0 ponto de partida e de chegada das relações sociais de poder é o acesso aos recursos. Ora, se o trabalho é um dos meios de tentativa de acúmulo de riquezas, ele raramente é o melhor: a aliança e a herança são bem mais rápidas. Todavia, a liberdade de escolha de suas alianças, a possibilidade de estabelecer uma filiação legítima e de pretender receber ou transmitir uma herança, são regradas pela heterossexualidade. 0 tema foi insuficientemente explorado. De fato, se na França, desde os anos de 1970, Christine Delphy (1998) teve a intuição da importância, para as relações sociais de sexo, da transmissão do patrimônio, mas não prosseguiu esta 
via. Foi somente bem mais tarde que pesquisadoras como Carmen Diana Deere et Magdalena León (2001) se lançaram num estudo sistemático da legislação do casamento e da herança na América Latina e no Caribe, convencidas de que era bem mais fácil uma melhoria na condição das mulheres por meio do acesso à propriedade (em ocorrência, da terra) do que ao assalariamento. No entanto, falta a esta análise uma reflexão crítica sobre o casamento e a família, como um dos grandes centros de exploração do trabalho "considerado feminino".

0 "casamento" não-heterossexual pode realmente subverter esta organização do trabalho e do acesso aos recursos? A este respeito, as lutas dos movimentos lésbicos, gays, bi, trans e queer merecem ser examinadas com cuidado, pois são ambivalentes. De um lado, obter de certos estados ${ }^{15}$ um início de direito ao casamento e à herança permite abrir uma brecha. Porém, a dificuldade em avançar no reconhecimento da filiação revela a ameaça que esta reivindicação representa: 0 problema talvez não seja tanto o suposto bem-estar psíquico das crianças, mas sim a possibilidade de fazer circular o patrimônio social e econômico de acordo com linhagens que não seriam as da família patriarcal e patrilinear dominante - a este respeito as coletâneas de textos sobre as sociedades matrilineares e/ou uxorilocais de Nicole Claude Mathieu (2007) traz uma luz particularmente importante. Não basta mudar o sexo do(a)s noivo(a)s para alterar as estruturas das relações sociais (MATHIEU, 1991 [1989]). De fato, para além do "casal”, se não tentamos colocar em prática outros arranjos "econômico-sexuais" - para retomar o conceito de Tabet (2004) - entre as pessoas, pouca coisa mudará (FALQUET, 2006 b). Como Wittig (2001 [1980]) havia claramente indicado, não é sobre a sexualidade lésbica (homossexual ou queer), como uma sexualidade "outra", que se deve debruçar, mas sim sobre a heterossexualidade como instituição.

Lembremos, antes de qualquer coisa, que a heterossexualidade constrói e naturaliza os sexos - tanto para a sexualidade como para o trabalho. Em todo caso, é assim que podemos ler Lévi-Strauss: segundo Gayle Rubin, afirmando que é a divisão sexual do trabalho, socialmente construída, que obriga a formação de unidades "familiares" que compreendem ao menos uma mulher e um homem, Lévi-Strauss chegou perigosamente perto de dizer que a heterossexualidade é um processo instituído. Ela mostrou também que a divisão sexual do trabalho funcionava graças ao tabu da homossexualidade (1998 [1975]). Enfim,

\footnotetext{
15 Apesar da impossibilidade de desenvolver aqui, é preciso enfatizar que estas reformas podem ser analisadas como um meio de certos governos social-democratas ganharem um pouco de legitimidade no plano societal aplicando, por outro lado, políticas econômicas neoliberais brutais.
}

RePensar AS RELAÇÕES SOCIAIS DE SEXo, CLASSE E “RAÇA”... 
independentemente de suas práticas sexuais reais, a ameaça de ser estigmatizada como lésbica éum potente meio de negar a qualquer mulher o acesso aos "trabalhos de homens" os mais prestigiosos e os melhores remunerados (PHARR, 1988). Foi isto que Monique Wittig (2001 [1980]) condensou em sua afirmação lapidar: "as lésbicas não são mulheres". De fato, ao se recusarem conscientemente de se unir a homens, algumas mulheres se recusam a trabalhar para eles - são estas que Wittig chamou de lésbicas, para diferenciá-las das mulheres que, embora tenham práticas homossexuais, não questionam seus laços de trabalho com os homens. Todavia, enquanto não admitirmos que a heterossexualidade não constrói apenas o sexo, a questão da apropriação coletiva das mulheres (GULLAUMIN, 1992 [1978]) permanecerá intacta.

A heterossexualidade intervém também no processo de reprodução e de naturalização da "raça" e da classe. Potente é o mito segundo o qual os proletários e o(a)s racializado(a)s nascem "naturalmente" da união heterossexual de dois proletários ou de duas pessoas racializadas. No entanto, nada é mais complexo do que asseguar uniões socialmente convenientes. Se tomarmos o caso das tensões em torno da produção da "raça", é interessante ver como uma das mais importantes provas de solidariedade de "raça" que os homens "racializados" pedem às mulheres "racializadas" é, com frequiência, de se casarem com eles e de criarem seus filhos. Esta questão que ocupa o cerne do nacionalismo (YUVAL DAVIS, 1997), afligiu os povos colonizados, atravessou o Movimento Negro nos Estados Unidos (SMITH, 1983) e hoje interroga o(a)s descendentes de imigrantes. Pois a racialização da heterossexualidade não é a mesma de acordo com os sexos: para muitos homens a exogamia "racial" é um direito, enquanto que para a maioria das mulheres a endogamia "racial" é um dever sagrado. 0 que está em jogo, tanto para as maiorias como para as minorias, na constituição da união de mulheres racializadas com homens mais "claros", merece ser aprofundado de acordo com os contextos históricos e políticos. Sobretudo porque recorta as questões de classe, em que a heterossexualidade intervém fortemente, mas com expectativas sexuais diferentes. Neste domínio, estima-se normal que as mulheres se casem com homens de uma classe superior ou igual à sua: é preciso analisar no que a fidelidade de classe que se espera delas se diferencia da fidelidade de "raça".

Assim, deve-se prosseguir com a reflexão com vistas a compreender como o sistema da heterossexualidade, fortemente estruturado pelas leis e políticas do Estado nacional, organiza a circulação de pessoas de acordo com o sexo, a classe e a "raça", o mesmo ocorre com a possibilidade de acesso ao mercado do trabalho 
remunerado, à aliança, à filiação, à legitimação e à posse das crianças e, enfim, à herança. Estado nacional e sistema heterossexual são estreitamente unidos para regulamentar a circulação das pessoas, de seus descendentes e sua capacidade de contrato são pilares do acesso ao trabalho assalariado - sem mencionar a propriedade. 0 que permite dar uma resposta bem mais complexa à questão de Balibar e Wallerstein: como se assegura a atribuição da mão-de-obra sobre 0 continuum trabalho assalariado-trabalho desvalorizado-trabalho gratuito? Para responder rapidamente, sob a égide do Estado e das Instituições internacionais como a instituição heterossexual, a ilegalidade e mesmo a criminalização crescente da migração, a ausência de estatuto autônomo para a maioria das mulheres imigrantes e a recusa de cidadania oposta a inúmeras mulheres pobres e racializadas, imigrantes e descendentes de imigrantes em diferentes partes do mundo e até mesmo em seu próprio país, contribuem fortemente para organizar a divisão do trabalho e, logo, para co-formar as relações sociais de sexo, de "raça" e de classe da globalização neoliberal.

Para concluir, é preciso reafirmar que o que propus aqui são apenas hipóteses de trabalho esboçadas e in progress. Diante da complexidade que de cara é colocada pela perspectiva da co-formação das relações sociais de sexo, de "raça" e de classe, é grande a tentação de renunciar a qualquer outra análise muito empírica e bastante localizada. Arrisquei puxar alguns fios para tentar melhor compreender a globalização neoliberal. Podemos constatar que permanecem particularmente vastos os campos a serem explorados. Recapitular "resultados" é igualmente difícil: a co-formação convida a aprofundar cada pista aberta estudando todas as suas ramificações. Aqui prefiro assinalar uma derradeira questão, que me parece capital: aquela dos mecanismos de coerção e de legitimação postos em prática para assentar a extensão da globalização neoliberal.

De fato, os estados dominantes e as instituições internacionais que se revezam tentam nos colocar todos e todas, qualquer que seja o país, pela persuasão midiática ou pela força das armas, frente a uma falsa alternativa. Simplificando, temos a escolha entre dois futuros. Um, dirigido pelos Estados Unidos com inúmeros apoios internacionais, nos mergulha numa perspectiva de guerra sem fim conduzida por aqueles que, em outro trabalho, denominei "homens em armas" (FALQUET, 2006). Mesmo que o presidente Bush pretenda combater um 
inimigo armado (o "terrorismo integrista muçulmano"), na realidade existe uma cumplicidade objetiva entre diferentes grupos de "homens em armas" cuja oposição é superficial, contra a população "civil" cujo paradigma seriam as "mulheres de serviço" realizando o "trabalho considerado feminino". Esta guerra permanente permite ao mesmo tempo submeter o conjunto da população ao controle de segurança, de lhe fazer esquecer seus interesses econômicos imediatos em benefício de ideais nacionalistas e de separar as "raças", acumulando enormes lucros. 0 outro futuro não encontra dificuldades para se apresentar como sedutor. Trata-se do projeto social-democrata "europeu" de semi-pleno emprego, de igualdade entre homens e mulheres e de cidadania ampliada e participativa, profundamente reorganizado para também permitir mais lucro.

É interessante notar que dos dois lados, para tentar legitimar o projeto, o discurso da igualdade entre os sexos é mobilizado de modo perverso, mesmo se tanto um como outro criam mais pobreza e violência para a maioria das mulheres. Do lado da "guerra das civilizações", vê-se facilmente que o discurso pseudofeminista de Bush prometendo "libertar as mulheres afegãs", e descrito por Zillah Eisenstein como "feminismo imperial", não passa de um discurso imperial típico das savior narratives tão bem descritas por Spivak (apud LANDRY \& MAcLEAN, 1996), servindo para justificar todas as intervenções (neo)coloniais. Permite também, como sabemos, fazer as mulheres dos países do Norte acreditarem que elas ocupam uma posição invejável, pois seriam "mais liberadas" que as outras (MOHANTY, 2003). Do lado da neo-social-democracia, a mensagem é mais sutil, mas também enganosa. Com efeito, um certo número de reformas legais a favor das mulheres, das "minorias" sexuais, acompanha um discurso encantado sobre 0 acesso cada vez mais igualitário das mulheres ao trabalho assalariado, à política e à cidadania. Este discurso se combina com políticas públicas, notadamente migratórias, que garantem certa substituição para o "trabalho considerado feminino" a uma minoria de mulheres e a uma maior parte de homens, com vistas a permitir mais exploração no trabalho assalariado e, sobretudo, em detrimento de vastas camadas da população mundial. Aqui, ainda, vemos que esta solução não poderia ser considerada satisfatória, pois é obrigatoriamente construída sobre a exploração daquelas e daqueles que realizam o "trabalho considerado feminino", particularmente sobre uma profunda divisão inernacional, racista e sexista do trabalho.

Éaindamaisimportanteultrapassarafalsaaternativadessesdoisprojetos, na verdade, irmãos siameses. Estes são hipocritamente propostos/impostos ao conjunto 
do(a)s habitantes do planeta, quando na verdade correspondem aos interesses de uma estreita minoria e que se sustentam em bases que tornam impossível a extensão de seus "benefícios" ao resto da população mundial. 0 componente radical do movimento feminista, como as franjas radicais dos movimentos contra 0 racismo e anticapitalistas, nos ensinou a esperar mais. 0 neoliberalismo não merece rearrumações. Por lutas que confrontam simultaneamente a divisão sexual, social e "racial" do trabalho, a globalização pode adquirir outras caras, mais adequadas à extinção progresiva ou imediata das relações sociais de poder. Mas não é sucumbindo ao canto das sereias daquelas e daqueles que preconizam lutar "contra uma única relação" que obteremos vitórias significativas. Pois a co-formação das relações sociais não é uma vã palavra e a responsabilidade do "trabalho considerado femino" diz respeito a todo mundo.

\section{REFERÊNCIAS}

AGIER, Michel. La main gauche de l'Empire: Ordre et désordres de l'humanitaire. Multitudes, $\mathrm{n}^{\circ} 11$, 2003. Disponível em: http://terra.rezo.net/article344.html ANDERSON, Bridget. Doing the dirty Work? The global politics of domestic labour. London: Zed Books, 2000.

ATTAC. Quand les femmes se beurtent à la mondialisation. Paris: Mille et une nuits, 2003.

BALIBAR, Etienne; WALLERSTEIN, Immanuel. Race, nation, classe: les identités ambiguës. Cahiers libres. Paris: La Découverte, 1997 [1988].

BACCHETTA, Paola. Quand les mouvements lesbiens à Delhi questionnent les 'théories féministes transnationales'. In: FALQUET, Jules; LADA, Emmanuelle; RABAUD, Aude (orgs.) (Ré)articulation des rapports sociaux de sexe, classe et "race". Repères historiques et contemporains. Cabiers du CEDREF. Paris: Université Paris-Diderot, 2006.

BETTIO Francesca; PLANTENGA, Janneke. Comparing care regimes in Europe, Feminist Economics, 10 (1), mars 2004.

BETTIO, Francesca; SIMONAZZI, Anna Maria; VILLA P. Change in care regimes and female migration: the "care drain" in the Mediterreanean. Journal of European Social Policy, 16 (3), 2006. 
BISILLIAT, Jeanne (org.). Femmes du Sud, chefs de famille. Paris: Karthala, 1996.

. Regards de femmes sur la globalisation. Approches critiques. Paris: Karthala, 2003.

BRAUDEL, Fernand. La Dynamique du capitalisme. Paris: Arthaud, 1985.

CHANG, Grace. Disposable Domestics: Immigrant Women Workers in the Global Economy. Cambridge, MA: South End Press, 2000.

CHAUDHURI, Kirti Narayan. Asia before Europe: Economy and Civilization of the Idian Ocean from the Rise of Islam to 1750. Cambridge: Cambridge University Press, 1990 .

COMBAHEE RIVER COLLECTIVE. Déclaration du Combahee River Collective. In: FALQUET, Jules et alii. (org.). (Ré)articulation des rapports sociaux de sexe, classe et "race". Repères historiques et contemporains. Cahiers du CEDREF. Paris: Université Paris-Diderot, 2006. [Primeira edição: Black Feminist Statement. In: EISENSTEIN, Zillah. Capitalist Patriarchy and the Case for Socialist Feminism (Monthly Review Press, 1979)].

CRENSHAW, Kimberle. The Intersection of Race and Gender. In: CRENSHAW, Kimberle; GOTANDA, Neil; PELLER, Garry; THOMAS; Kendal (eds.). Critical Race Theory. The Key Writings That Formed the Movement. New York: New Press, 1995.

DAVIS, Angela. Les goulags de la démocratie. Réflexions et entretiens. Paris: Au diable vauvert, 2006. [Primeira edição: Abolition Democracy. Beyond Empire, Prisons and Torture. New York: Seven Stories Press, 2005].

. Femmes, race et classe, Paris: Des femmes, 1983. [Primeira edição em inglês, Random House, New York, 1981].

DEERE, Carmen Diana; LEON, Magdalena. Empowering Women: Land and Property Rights ine Latin America. Pittsburgh: University of Pittsburgh Press, 2001.

DEGAVRE, Florence; NYSSENS, Marthe. Paid and unpaid care to elderly people: the case of home care workers in Belgium. Comunicação no colóquio Production and distribution of well being into the family: strategies of remunerated and non-remunerated labour and consumption patterns. Université de Barcelone, junho de 2007. 
DELPHY, Christine. L'ennemi principal. 1: Economie politique du patriarcat. Paris: Syllepses, 1998.

EHRENREICH, Barbara; HOCHSCHILD, Arlie Russel. Global Woman: Nannies, Maids and Sex Workers in the New Economy. New York: Metropolitan Books, 2003.

EISENSTEIN, Zillah. Against Empire: feminisms, racism and the West. London, New York: Zed Books; Melbourne: Spinifex Press, 2004.

ENLOE, Cynthia. Bananas, beaches and bases: making sense of international politics. Berkeley: University of California Press, 1989.

ENLOE, Cynthia. Manewvers: the international politics of militarizing women's lives. Berkeley and London: University of California Press, 2000.

FALQUET, Jules; HIRATA, Helena; LAUTIER, Bruno. Travail et mondialisation: confrontations Nord-Sud. Cabiers du Genre, n40, 2006.

FALQUET, Jules. Hommes en armes et femmes "de service": tendances néolibérales dans l'évolution de la division sexuelle et internationale du travail. Cahiers $d u$ Genre, Travail et mondialisation. Confrontations Nord/Sud, n 40, 2006.

. Le couple, "ce douloureux problème". Vers une analyse matérialiste des arrangements amoureux entre lesbiennes. Actes du 5ème colloque international d'études lesbiennes "Tout sur l'amour (sinon rien)". Toulouse: Bagdam Espace Lesbien, 2006 b.

. Femmes, féminisme et "développement": une analyse critique des politiques des institutions internationales". In: BISILLIAT, Jeanne (org.). Regards de femmes sur la globalisation. Approches critiques. Paris: Karthala, 2003.

FASSIN, Didier; MORICE, Alain; QUIMINAL, Catherine. (orgs.).. Les lois de l'inhospitalité. Les politiques de l'immigration à l'épreuve des sans-papiers. Paris: La Découverte, 1997.

GILROY, Paul. L'Atlantique noir. Modernité et double conscience. Paris: Kargo, 2003. [Primeira edição: The Black Atlantic. Modernity and Double Consciousness, 1993]

GUILLAUMIN, Colette. Pratique du pouvoir et idée de nature. In: Sexe, race et pratique du pouvoir. Lidée de Nature. Paris: Côté-femmes, 1992. [Publicado inicialmente em Questions Féministes, n 2 e 3, fevereiro e maio de 1978].

GUILLEMAUT, Françoise. Stratégies des femmes en migration: pratiques et 
pensées minoritaires. Repenser les marges au centre. Thèse de sociologie et sciences sociales. Université de Toulouse 2, 2007.

HILL COLLINS, Patricia. Black Sexual Politics. African Americans, Gender and the New Racism. New York \& London: Routledge, 2005.

HIRATA, Helena; LE DOARE, Hélène. (orgs.). Les Cahiers du GEDISST, n² 21. Les paradoxes de la mondialisation. Paris: L'Harmattan, 1998.

HOCHSCHILD, Arlie Russel. Global Care Chains and Emotional Surplus Value. In: HUTTON, W.; GIDDENS, Antony (orgs.). On the Edge: Living with Global Capitalism. New York: Free Press, 2000.

HOCHSCHILD, Arlie Russel. Love and Gold. In: EHRENREICH, B.; HOCHSCHILD, A. R. (orgs.). Global Women: Nannies, Maids and Sex Workers in the New Economy. New York: Henry Holt and Company, 2002.

HONDAGNEU-SOTELO, Pierrette. Domestica: Immigrant Workers Cleaning and Caring in the Shadows of Affluence. Berkeley: University of California Press, 2001. KAHN, Susan Martha. Les enfants d'Israël. Une approche culturelle de l'assistance médicale à la procréation. Paris: L'Harmattan, Bibliothèque du féminisme, 2007.

KERGOAT, Danièle. Dynamique et consubstantialité des rapports sociaux. In: DORLIN, Elsa (org.). Sexe, classe, race. Pour une épistémologie de la domination. Paris: PUF, 2008.

KOFMAN, Eleonore; PHIZUCKLEA, Annie; RAGHURAN, Parvati; SALES, Rosemar. Gender and International Migration in Europe: Employment, Welfare, and Politics. London: Routledge, 2001.

LANDRY, Donna, MAcLEAN, Gerald (orgs.). The Spivak Reader. New York and London: Routledge, 1996.

LESSELLIER, Claudie. Femmes migrantes en France: le genre et la loi. In: HERSENT, Madeleine; ZAIDMAN, Claude (orgs.). Genre, travail et migrations en Europe. Cahiers du CEDREF, 2003.

MARCHAND, Marianne; SISSON RUNYAN, Anne (orgs.). Gender and Global Restructuring. London and New York: Routledge, 2000.

MATHIEU, Nicole Claude. Identité sexuelle / sexuée / de sexe ? Trois modes de conceptualisation du rapport entre sexe et genre. In: L'anatomie politique, Catégorisations et idéologies du sexe. Paris: Côté Femme, 1991. [Primeira edição 
em DAUNE, Richard et alli., Catégorisation de sexe et constructions scientifiques. Aix: Université de Provence, 1989].

. (org.). Une maison sans fille est une maison morte. La personne et le genre en sociétés matrilinéaires et/ou uxorilocales. Paris: Editions de la Maison des Sciences de l'Homme, 2007.

MOHANTY, Chandra. Feminism Without Borders. Decolonizing Theory, Practicing Solidarity. Duke University Press: Durham \& London, 2003.

MOUJOUD, Nasima. Migrantes seules du Maroc sans papiers en France: dominations imbriquées et résistances individuelles. Thèse de doctorat en Anthropologie. Paris: EHESS, 2007.

MOULIER BOUTANG, Yann. De l'esclavage au salariat. Économie historique du salariat bridé. Paris: PUF, 1998.

NAKANO GLENN, Evelyn. Unequal Freedom: How Race and Gender Shaped American Citizenship and Labor. Cambridge, MA: Harvard University Press, 2002.

OSO, Laura. Migration et trafic de femmes latino-américaines en Espagne: service domestique et prostitution. In: ZAIDMAN \& HERSENT (orgs.). Genre, travail et migrations en Europe. Cabiers du CEDREF, 2003.

Migration, genre et foyers transnationaux: un état de la bibliographie. Cabiers du CEDREF, no prelo.

PAPERMAN, Patricia, LAUGIER, Sandra. Le souci des autres. Ethique et politique $d u$ care. Paris: Editions de l'Ecole des hautes Etudes en Sciences Sociales, 2005.

PARRENAS, Rhacel.Servants of Globalization. Women, Migration and Domestic Work. Standford: Standford University Press, 2002.

PHARR, Suzanne. Homophoby: a weapon of sexism. Little Rock: Chardon Press, 1988.

PHETHERSON, Gail.Leprisme de la prostitution. Paris: L'Harmattan, Bibliothèque du féminisme, 2001. [Primeira edição: The Prostitution Prism. Amsterdam University Press, 1996].

RAVENSTEIN, Ernest George. The laws of migration, Journal of the Statistical Society, London, 48 (2), 1985.

RUBIN, Gayle. L'économie politique du sexe: transactions sur les femmes et systèmes de sexe/genre. Paris: Cahiers du CEDREF nº 7, 1998. [Primeira edição 
em inglês: The Traffic in Women: Notes on the 'political economy' of sex. In: REITER, Rayna (org.). Toward an Anthropology of Women. New York and London, Monthly Review Press, 1975].

SAINSBURY, Diane. Gendering Welfare States. London: Sage (Modern Politics Series), 1993.

SASSEN, Saskia. The Global City: New York, London, Tokyo. Princeton, N. J.: Princeton University Press, 1991.

SMITH, Barbara. (org.). Home girls: a black feminist anthology. New York: Kitchen Table/Women of Color Press, 1983.

STRÖBL, Ingrid. Fruto extraño. Sobre política demográfica y control de población. Montevideo: Cotidiano Mujer, 1994. [Primeira edição em alemão, 1991].

TABET, Paola. Fertilité naturelle, reproduction forcée. In: La construction sociale de l'inégalité des sexes. Des outils et des corps. Paris: L'Harmattan, Bibliothèque du féminisme, 1998. [Primeira edição In: MATHIEU, Nicole Claude. L'arraisonnement des femmes. Paris: Editions de l'EHESS.]

La grande arnaque. Sexualité des femmes et échange économicosexuel. Paris: L'Harmattan, Bibliothèque du féminisme, 2004.

TERRAY, Emmanuel. Le travail des étrangers en situation irrégulière ou la délocalisation sur place. In: BALIBAR, Etienne; CHEMILLIER GENDREAU, Monique; COSTA-LACOUX, Jacqueline; TERRAY, Emmanuel. Sans papiers: l'archaïsme fatal. Paris: La Découverte, 1999.

TRAVAIL, GENRE ET SOCIETE. Femmes providentielles, enfants et parents à charge. $\mathrm{n}^{\circ}$ 6, octobre 2001.

WALBY, Silvia. Theorizing Patriarchy. Oxford, Cambridge: Blackwell, 1990.

. Gender Transformations. London: Routledge, 1997.

WALLERSTEIN, Immanuel. The Modern World System (I, II \& III). New York: Academic et Cambridge University Press, 1974, 1980 e 1989.

WICHTERICH, Christa. La femme mondialisée. Paris: Solin, Actes Sud, 1999.

WITTIG, Monique. La pensée straight. Paris: Balland, 2001. [Primeira edição em francês: La pensée straight. Questions Féministes n 7, 1980; e 0n ne naît pas femme, Questions Féministes nº 8, 1980].

YUVAL-DAVIS, Nira. Gender and Nation. Londres: Sage Publications, 1997. 